\title{
Dynamic Game Analysis of Coal Electricity Market Involving Multi-Interests
}

\author{
Yu Xiaobao, ${ }^{1}$ Tan Zhongfu, ${ }^{1}$ Chen Kangting, ${ }^{1}$ and He Puyu ${ }^{2}$ \\ ${ }^{1}$ North China Electric Power University, Beijing 102206, China \\ ${ }^{2}$ Sichuan Electric Power Corporation Power Economic Research Institute, Chengdu 610000, China
}

Correspondence should be addressed to Yu Xiaobao; yuxiaobao1222@163.com

Received 7 April 2016; Accepted 8 August 2016

Academic Editor: Yan-Wu Wang

Copyright (c) 2016 Yu Xiaobao et al. This is an open access article distributed under the Creative Commons Attribution License, which permits unrestricted use, distribution, and reproduction in any medium, provided the original work is properly cited.

\begin{abstract}
The coal consumption of China reached 2.75 billion tons of standard coal in 2013, which accounted for $67.5 \%$ of total energy consumption and more than $50 \%$ of global coal consumption. Therefore, the impact of coal price is huge on coal market and even energy market in China. As a large consumer of coal, thermal power enterprise has a strong sensitivity to coal price. In order to balance the rising cost of enterprises due to coal price, we need to analyze the interests of multiple stakeholders. Firstly, this paper combined the Nash equilibrium and cobweb model and proposed the characteristics in different cobweb model. Then, for coal, power, and energy companies, the dynamic game analysis model is constructed. This model gives a game analysis in four scenarios and quantifies the decision of each stakeholder in different coal prices. Finally, the impact figure of different coal prices on each stakeholder has been drawn. The impacts of different coal or thermal power prices on different markets have been put forward, so relevant policy recommendations have been proposed combined with the cobweb model.
\end{abstract}

\section{Introduction}

Since liberalization of coal market, it has become a relatively free market in China, and coal prices are mainly affected by the coal market. At the same time, the strict control of electricity prices led to profit squeeze of thermal power enterprises in which coal is the main power resource, so thermal power enterprises are dissatisfied to the control of tariff, and then there is the so-called "Coal-Power Struggle" [1]. National Development and Reform Commission expected to weaken contradiction between coal and thermal power enterprises through "coal linkage." This method has temporarily alleviated the price competition between them, but due to the high cost and limited price upside, "coal linkage" will be restricted, so coal price contradiction is still prominent, electricity production still faces great pressure, and the coal-electricity linkage cannot really solve the price competition problem [2].

Many scholars have put forward their views on how to solve the contradiction between coal and electricity. In literature [3], according to analysis framework of new experiences industrial organization and GMM method, it estimates the potential welfare losses of coal industry chain and market forces of coal and power industry in China from 2005 to 2008 and draws the conclusion: Coal and thermal power industry market force premium are 1.10 and 0.87 . The market power of coal industry and high cost of thermal power industry with price regulation are the main reason for the contradiction. In literature [4], the scholar proposed to speed up the reform of the electricity market. The government needs to regulate the sales price. Based on the supply chain cooperation, this literature designed the overall framework of the revenue coordination mechanism and government subsidy coordination mechanism under government regulation. In literature [5], on the basis of origin analysis for coal contradiction, it builds static game model between coal yard, power plants, and government and derives the optimal selection result.

From an economic point, "Coal-Power Struggle" is a typical game between coal industry and electricity industry. In order to maximize their own interests, participants make a fuss in coal price. In this paper, the dynamic game theory is used to study the competition between coal and electric 


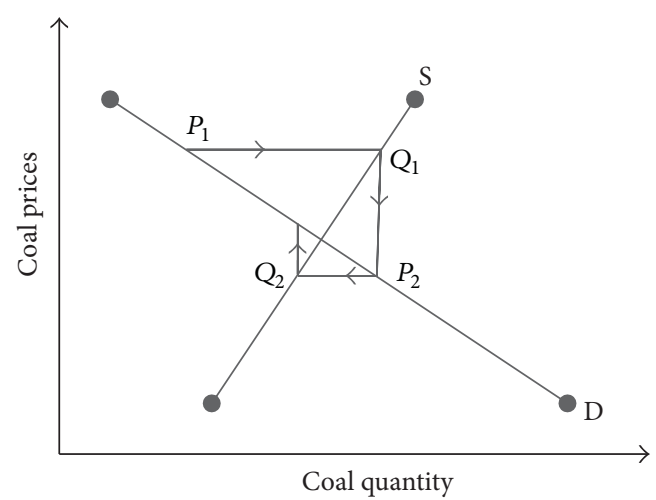

FIGURE 1: Convergence cobweb model of coal market.

power enterprises in coal and electricity price. The game third party-energy consuming enterprise has been added. The choice of energy companies can feedback coal price. Simultaneously, based on the construction of dynamic game analysis model, characteristics of coal market are derived under different scenarios, so cobweb model could be defined and corresponding policies would be put forward. Finally, according to relationships of different coal market parameters under different scenarios, related proposals will be made for Nash equilibrium of coal market.

\section{Nash Equilibrium and Cobweb Model}

Nash equilibrium $[6,7]$ is a kind of strategy combination, which makes each participant the best response to other participants. For multiple players in the game, if no one can increase profit alone, this strategy is called Nash equilibrium. The Nash equilibrium does not mean that the two parties are in a state but is reached in the continuous action of the game.

Cobweb model mentioned in macroeconomics is divided into three types, including convergence cobweb, closed cobweb, and divergent cobweb. Among them, convergence cobweb and closed cobweb are different performance to reach Nash equilibrium. When there are other generation sources in coal market, demand and supply of commodity coal will be affected. According to the slope of demand and supply curves, there are three cobweb models.

(1) When the slope absolute value of supply curve is greater than demand curve, it means demand elasticity is large. So small price changes will cause the smaller supply changes and vice versa. When market deviates from the original equilibrium state due to interference, the actual price and output will fluctuate around the equilibrium level, but the magnitude of fluctuation is getting smaller and then reverts to the original equilibrium, which constitutes the convergence cobweb model, as shown in Figure 1.

(2) When the slope absolute value of supply curve is less than demand curve, it means supply elasticity is large. So impact of price on supply is greater than that of demand, and the fluctuation will gradually increase

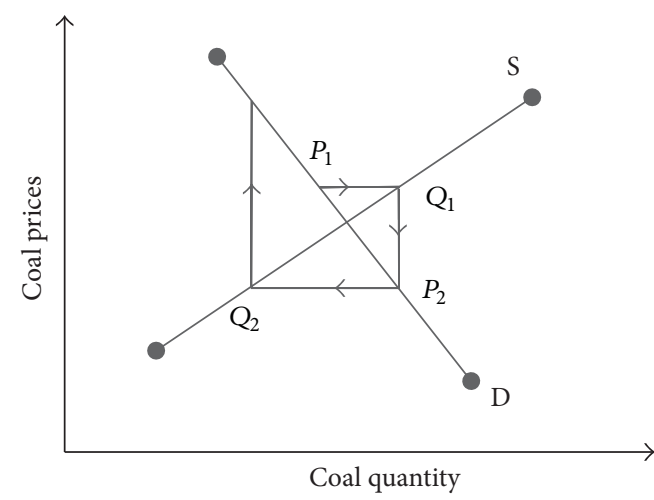

FIGURE 2: Divergent cobweb model of coal market.

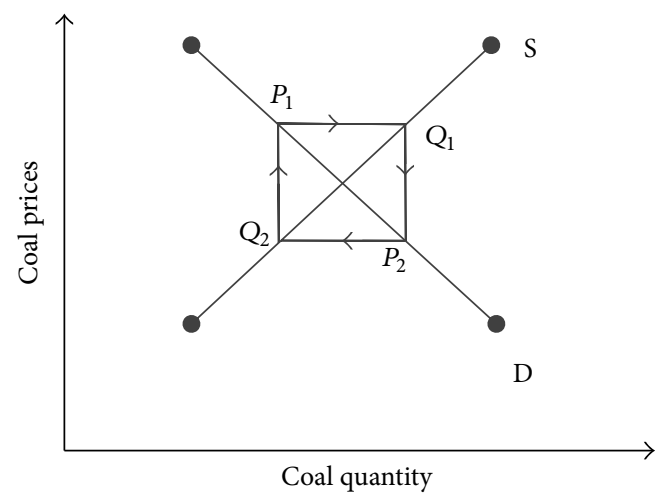

FIGURE 3: Closed cobweb model of coal market.

and cannot restore equilibrium, which constitutes the divergent cobweb model, such as that shown in Figure 2.

(3) When the slope of the two curves is equal, it means the elasticity of supply is equal to demand and the volatility will continue to cycle, which neither is far away from the equilibrium point nor returns to equilibrium, which constitutes the closed cobweb model, as shown in Figure 3.

\section{Dynamic Game Analysis Model}

Dynamic game [8-10] means actions of participants have a sequence. The latter can observe the previous selection and then makes the appropriate choice. Dynamic game can be divided into the first-mover advantage and late-mover advantage. Generally, output competition has first-mover advantage and price competition has the late-mover advantage. Coal-electricity market is semifree and semimarket. The coal sales market is basically in a state of free competition, while the net price and sales price are still in a planned state. But with the acceleration of electricity reform, coal-electricity market will be dominated by its own market [11, 12]. When this paper analyzes all interest parties of dynamic game in the market, the generation, transmission, distribution, and sale of electricity are tied together. Without regard for energy 


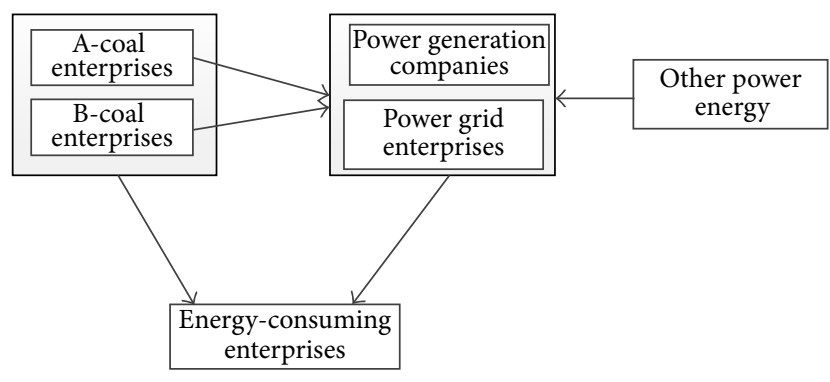

FIGURE 4: Overall framework of coal-electricity market.

loss and other factors, it is more convenient to analyze the research emphasis of this paper, that is, the dynamic game of the coal-electricity market.

3.1. Premise Hypothesis. The research of this paper is to analyze the impact of coal price and electricity price fluctuation on stakeholders in coal-electricity market. Therefore, there are some hypotheses when we discuss the results of game analysis.

(1) Combine economic man hypothesis with relevant policies; that is, the stakeholder only considers his own total revenue and total cost and will use the policy provisions in exceptional circumstances.

(2) Fixed costs of coal and power generation enterprises do not change with the change of output, and different types of power generation do not affect the fixed costs.

(3) The total energy consumption of coal-electricity market is fixed, and total demand is less than the largest supply.

(4) Electrical energy produced by coal is used for sale, without considering auxiliary power and line loss. The different cost of electrical energy produced by other energy is not taken into account but is set to the marginal cost of power generation.

(5) There are four kinds of enterprises in the market, including coal enterprises, power enterprises, other energy companies, and energy consuming enterprises. Among them, taking freedom of the coal market into account, this paper sets up two coal enterprises and only one for other types.

(6) When the coal market is analyzed separately, there is a competition between different coal enterprises. But for the comprehensive analysis, there is no difference between the two coal companies.

3.2. Model Design. The dynamic game analysis model for coal-electricity market mainly involves four enterprises and constitutes a variety of game paths according to the interests among enterprises. The overall model of coal-electricity market is shown in Figure 4.

From Figure 4, there are some benefit relationships among units, as follows:
(1) The coal volume that coal enterprise A sold to energy consuming enterprise is $q_{1}$, the price is $p_{c}$, the marginal cost is $m_{1}$, and the fixed cost is $C_{1}$ (not a specific value), so the profit formula of $\mathrm{A}$ form energy consuming enterprise is

$$
\pi_{\mathrm{A} 1}=p_{c} \cdot q_{1}-m_{1} q_{1}-C_{1} .
$$

(2) The coal volume that coal enterprise B sold to energy consuming enterprise is $q_{2}$, the price is $p_{c}$, the marginal cost is $m_{1}$, and the fixed cost is $C_{1}$, so the profit formula of $\mathrm{B}$ form energy consuming enterprise is

$$
\pi_{\mathrm{B} 1}=p_{c} \cdot q_{2}-m_{1} q_{2}-C_{1} .
$$

(3) The coal volume that coal enterprise A sold to power generation enterprise is $q_{3}$, the price is $p_{c}$, the marginal cost is $m_{1}$, and the fixed cost is $C_{1}$, so the profit formula of A form power generation enterprise is

$$
\pi_{\mathrm{A} 2}=p_{c} \cdot q_{3}-m_{1} q_{3}-C_{1} .
$$

(4) The coal volume that coal enterprise B sold to power generation enterprise is $q_{4}$, the price is $p_{c}$, the marginal cost is $m_{1}$, and the fixed cost is $C_{1}$, so the profit formula of $\mathrm{B}$ form power generation enterprise is

$$
\pi_{\mathrm{B} 2}=p_{c} \cdot q_{4}-m_{1} q_{4}-C_{1} \text {. }
$$

(5) The marginal cost of other power is $m_{3}$. Considering the government subsidies for clean energy, we set average subsidy as $m_{4}$. Amount of clean energy is $Q_{w}$, so the cost for power generation companies with the use of clean energy is

$$
C_{w}=Q_{w} \cdot\left(m_{3}-m_{4}\right)
$$

(6) Average price of thermal power is $p_{f}$, and average price of other energy is $p_{w}$. Coal consumption rate of thermal power or other energy is $\varphi, \psi$.

$$
C_{u}=p_{c}\left(q_{1}+q_{2}\right)+p_{f} \frac{\left(q_{3}+q_{4}\right)}{\varphi}+p_{w} \frac{q_{w}}{\psi} .
$$

Among them, the total demand for energy consumption enterprises is fixed as $Q$. The total amount of energy consumption is equal to the total demand; that is,

$$
C_{u}=\sum_{i=1}^{4} q_{i}+\frac{q_{w}}{\psi}
$$

3.3. Dynamic Game Path. This paper mainly analyzes the impact of coal price or electricity price fluctuation on coalelectricity market, so the starting point of dynamic game is the coal price fluctuation. Effects of coal price fluctuation on electricity price or other energy prices will affect sales of coal and then make coal price feedback, which constitutes a number of loops. The loop is defined as dynamic game path, as shown in Figure 5.

Path 1. Coal price rise $\rightarrow$ purchase cost of coal for energy consuming enterprises increase $\rightarrow$ coal demand of energy 


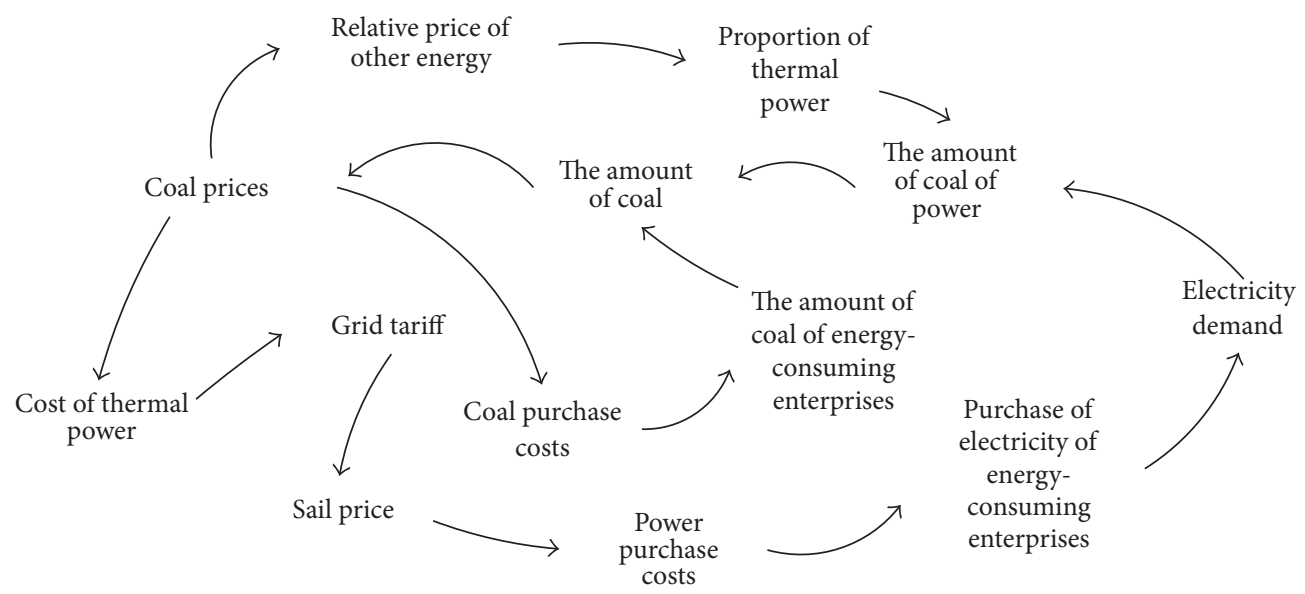

Figure 5: Dynamic game feedback loop.

consuming enterprises reduction $\rightarrow$ total coal purchase reduction $\rightarrow$ coal price decline.

Path 2. Coal price rise $\rightarrow$ thermal power cost increase $\rightarrow$ on-grid tariff rise $\rightarrow$ sales tariff rise $\rightarrow$ purchase cost of electricity for energy consuming enterprise increase $\rightarrow$ power demand reduction $\rightarrow$ coal consumption for electricity decline $\rightarrow$ total coal purchase reduction $\rightarrow$ coal price decline.

Path 3. Coal price rise $\rightarrow$ price of other energy reduction $\rightarrow$ proportion of thermal power decline $\rightarrow$ coal consumption for electricity decline $\rightarrow$ total coal purchase reduction $\rightarrow$ coal price decline.

Implied Path 1 . Cost of coal and electricity rise $\rightarrow$ growth rate contrast $\rightarrow$ growth rate of coal is less than electricity $\rightarrow$ coal purchase quantity increase $\rightarrow$ coal price rise.

Implied Path 2. Cost of coal and electricity rise $\rightarrow$ growth rate contrast $\rightarrow$ growth rate of coal is more than electricity $\rightarrow$ coal purchase quantity decline $\rightarrow$ coal price drop.

Implied Path 3. Coal purchase of energy consuming enterprise increase and coal purchase of developed enterprise decrease $\rightarrow$ growth rate contrast $\rightarrow$ coal purchase quantity increase $\rightarrow$ coal price rise.

Implied Path 4. Coal purchase of energy consuming enterprise increase and coal purchase of developed enterprise decrease $\rightarrow$ growth rate contrast $\rightarrow$ coal purchase quantity decrease $\rightarrow$ coal price drop.

The path analysis above is based on the concept of free competition market. If we consider the government intervention, the situation will be changed and it will be analyzed by price changes of all kinds of energy $[13,14]$. At this point, different energy prices will constitute a competition, and this competition will change in the long term, and each kind of energy price will be adjusted according to other energy, so as to constitute a dynamic game path.

\section{Game Analysis}

4.1. Two Companies and One Kind of Energy. If there are only one coal enterprise, one energy consuming enterprise, and one kind of energy (coal), coal enterprises are divided into two, coal enterprise A and coal enterprises B. Among them, the total inventory of $\mathrm{A}$ is $q_{\mathrm{A}}$, and the total inventory of $\mathrm{B}$ is $q_{\mathrm{B}}$. They meet the following relationship:

$$
\begin{array}{r}
q_{\mathrm{A}}<\mathrm{Q}, \\
q_{\mathrm{B}}<\mathrm{Q}, \\
q_{\mathrm{A}}+q_{\mathrm{B}}>\mathrm{Q} .
\end{array}
$$

According to the premise, coal price fluctuation is for the entire coal industry, so the same coal price fluctuation for different coal enterprises can only cause different coal sales. This paper takes the order of sales into account and assumes that coal enterprise $A$ is priority to determine the sales volume. According to the design of model, if the coal enterprise $\mathrm{A}$ has determined the sales volume $q_{1}^{*}$, the coal market demand function is $Q=a-b p_{c}$, so the best choice analysis for B is as follows:

$$
\begin{aligned}
q_{1}^{*}+q_{2} & =Q, \\
p_{c} & =\frac{1}{b}\left(a-q_{1}^{*}-q_{2}\right), \\
\pi_{\mathrm{B}} & =\frac{1}{b}\left(a-q_{1}^{*}-q_{2}\right) q_{2}-m_{1} q_{2}-C_{1} .
\end{aligned}
$$

According to the profit function of coal enterprise $B$, the derivation of $q_{2}$ is

$$
\begin{aligned}
\frac{\partial \pi_{\mathrm{B}}}{\partial q_{2}} & =\frac{a}{b}-\frac{q_{1}^{*}}{b}-\frac{2 q_{2}}{b}-m_{1}=0, \\
q_{2} & =\frac{1}{2}\left(a-q_{1}^{*}-m_{1} b\right) .
\end{aligned}
$$


Using this result in profit function of $A$, we can get the derivation of $q_{1}^{*}$ :

$$
\begin{aligned}
\frac{\partial \pi_{\mathrm{A}}}{\partial q_{1}^{*}} & =\frac{a}{2 b}-\frac{q_{1}^{*}}{b}-\frac{m_{1}}{2}=0, \\
q_{1}^{*} & =\frac{1}{2}\left(a-b m_{1}\right) .
\end{aligned}
$$

With the outcome of $q_{1}^{*}$ and formula (11), we can calculate $q_{2}$; that is,

$$
q_{2}=\frac{1}{4}\left(a-b m_{1}\right) .
$$

According to the calculation result, we can get a conclusion: in the competition of coal companies $A$ and $B$, the output of company A that decides sales volume first is 2 times that of $B$, which is the so-called Starr Berg Equilibrium.

4.2. Three Enterprises and Two Kinds of Energy. If there are three companies, they are coal enterprise, electric power enterprise, and energy consuming enterprise. We only consider the thermal power and coal energy. The coal consumption rate of thermal power is $\varphi$, and fixed cost is $C_{2}$, so the profit function is

$$
\pi_{c}=p_{c} \sum_{i=1}^{4} q_{i}-m_{1} \sum_{i=1}^{4} q_{i}-C_{1} .
$$

Profit function of electric power enterprise is

$$
\pi_{e}=p_{f} \frac{q_{3}+q_{4}}{\varphi}-p_{c}\left(q_{3}+q_{4}\right)-C_{2} .
$$

The cost function and the constraint condition of energy consumption in the enterprise are

$$
\begin{aligned}
C_{u} & =p_{c}\left(q_{1}+q_{2}\right)+p_{f} \frac{\left(q_{3}+q_{4}\right)}{\varphi}, \\
\sum_{i=1}^{4} q_{i} & =Q .
\end{aligned}
$$

(1) Coal price rises, $\theta$, and tariff remains unchanged, so coal price is recorded as $p_{c}(1+\theta)$, and the cost function of energy consuming enterprise is

$$
C_{u}=p_{c}(1+\theta)\left(q_{1}+q_{2}\right)+p_{f} \frac{q_{3}+q_{4}}{\varphi}
$$

Among them, cost fluctuation function of energy consuming enterprise is

$$
\Delta C_{u}=\theta p_{c}\left(q_{1}+q_{2}\right) \geq 0 .
$$

Profit fluctuation function of electric power enterprises is

$$
\Delta \pi_{e}=-\theta p_{c}\left(q_{3}+q_{4}\right) \leq 0 .
$$

From the cost fluctuation function, we can see when the cost of energy consumption enterprise increases, the profit of power enterprise will reduce. If electricity price remains unchanged, energy consumption enterprise needs to consider adjusting the purchase proportion of coal and electricity. It is specifically divided into the following two cases:
(1) If $p_{c}(1+\theta) \leq p_{f} / \varphi$, it can infer that the energy consuming enterprise will maintain the current energy purchase ratio, so cost of power enterprise will be increased and profit will be declined.

(2) If $p_{c}(1+\theta)>p_{f} / \varphi$, it can infer that energy consuming enterprise will all use electric energy. In order to meet the power need, the power company will increase coal purchase quantity. According to energy consumption constraints, the total coal consumption is still the same; that is, the total amount of coal sales is $\sum_{i=1}^{4} q_{i}$. So the profit of power enterprise is

$$
\Delta \pi_{e}=p_{f} \frac{q_{1}+q_{2}}{\varphi}-p_{c}\left(q_{1}+q_{2}\right)-p_{c} \theta\left(q_{3}+q_{4}\right) .
$$

When coal price is fixed in above situation, if the coal price has increased, $\theta$, the change in profit of power enterprise would be $-p_{c} \theta\left(q_{3}+q_{4}\right) \leq 0$. In these two cases, as long as the price of coal increased and electricity price remained the same, the profit would reduce no matter how the power sales.

(2) Coal price increases $\theta$, and thermal power price increases $\varepsilon$, so the cost fluctuation function of energy consuming enterprise is

$$
\Delta C_{u}=\theta p_{c}\left(q_{1}+q_{2}\right)+\varepsilon p_{f} \frac{q_{3}+q_{4}}{\varphi} \geq 0
$$

Profit fluctuation function of electric power enterprises is

$$
\Delta \pi_{e}=\left(\frac{\varepsilon p_{f}}{\varphi}-\theta p_{c}\right)\left(q_{3}+q_{4}\right) .
$$

From the cost fluctuation function, we can see when the cost of energy consumption enterprise increases, the profit of power enterprise will be different according to different markup of two kinds of energy, specifically as follows:

(1) When $\varepsilon p_{f} / \varphi \leq \theta p_{c}, \Delta \pi_{e} \leq 0$, the profit of power enterprise is less than rising price.

(2) When $\varepsilon p_{f} / \varphi \geq \theta p_{c}, \Delta \pi_{e} \geq 0$, the profit of power enterprise is more than rising price.

For the cost fluctuation of energy consuming enterprise, the discussion is as follows:

(1) When $\theta p_{c}\left(q_{1}+q_{2}\right) \leq \varepsilon p_{f}\left(\left(q_{3}+q_{4}\right) / \varphi\right)$, energy consuming enterprise will increase the consumption of coal and reduce the consumption of electricity.

(2) When $\theta p_{c}\left(q_{1}+q_{2}\right) \geq \varepsilon p_{f}\left(\left(q_{3}+q_{4}\right) / \varphi\right)$, energy consuming enterprise will reduce the consumption of coal and increase the consumption of electricity.

4.3. Two Enterprises and Two Kinds of Energy. Assuming there are electric power enterprise and energy consuming enterprise, power generation energy includes coal and other 
energy. If coal enterprise cannot supply to energy consuming enterprise directly, the profit function of power enterprises is

$$
\begin{aligned}
\pi_{e}= & p_{f}\left(\frac{q_{3}+q_{4}}{\varphi}\right)+p_{w} \frac{q_{w}}{\psi}-p_{c}\left(q_{3}+q_{4}\right) \\
& -q_{w}\left(m_{3}-m_{4}\right) .
\end{aligned}
$$

(1) Coal price rises, $\theta$, and tariff remains unchanged, so coal price is recorded as $p_{c}(1+\theta)$, so the profit function of power enterprise after coal price change is

$$
\begin{aligned}
\pi_{e}^{\prime}= & p_{f}\left(\frac{q_{3}+q_{4}}{\varphi}\right)+p_{w} \frac{q_{w}}{\psi}-p_{c}(1+\theta)\left(q_{3}+q_{4}\right) \\
& -q_{w}\left(m_{3}-m_{4}\right) .
\end{aligned}
$$

Profit fluctuation function of electric power enterprise is

$$
\Delta \pi_{e}=-\theta p_{c}\left(q_{3}+q_{4}\right)
$$

From formula (25), it can be known that the profit of power enterprise must be down when coal price rises and thermal power price remains unchanged; then the power enterprise will consider adjusting the proportion of thermal power, specifically as follows:

(1) When $p_{f} / \varphi-p_{c}(1+\theta)>p_{w} / \psi-\left(m_{3}-m_{4}\right)$, the thermal power cost is still less than other energy and, even rising the price, power enterprise will not reduce the proportion of thermal power.

(2) When $p_{f} / \varphi-p_{c}(1+\theta)<p_{w} / \psi-\left(m_{3}-m_{4}\right)$, the thermal power cost is more than other energy, and power enterprise will reduce the proportion of thermal power.

(2) Coal price increases $\theta$, and thermal power price increases $\varepsilon$, so the profit function of electric power enterprise after price change is

$$
\begin{aligned}
\pi_{e}^{\prime}= & p_{f}(1+\varepsilon)\left(\frac{q_{3}+q_{4}}{\varphi}\right)+p_{w} \frac{q_{w}}{\psi} \\
& -p_{c}(1+\theta)\left(q_{3}+q_{4}\right)-q_{w}\left(m_{3}-m_{4}\right) .
\end{aligned}
$$

Profit fluctuation function of electric power enterprise is

$$
\Delta \pi_{e}=\varepsilon p_{f} \frac{q_{3}+q_{4}}{\varphi}-\theta p_{c}\left(q_{3}+q_{4}\right) .
$$

(1) If $\varepsilon p_{f} / \varphi \leq \theta p_{c}$, it means $\Delta \pi_{e} \leq 0$, so power enterprise will adjust the proportion of thermal power to reduce the loss.

(2) If $\varepsilon p_{f} / \varphi>\theta p_{c}$, it means $\Delta \pi_{e}>0$, so power enterprise will not adjust the proportion of thermal power.

(3) When $\varepsilon p_{f} / \varphi-p_{c}(1+\theta)>p_{w} / \psi-\left(m_{3}-m_{4}\right)$, the thermal power cost is still less than other energy and, even rising the price, power enterprise will not reduce the proportion of thermal power.

(4) When $\varepsilon p_{f} / \varphi-p_{c}(1+\theta)<p_{w} / \psi-\left(m_{3}-m_{4}\right)$, the thermal power cost is more than other energy, and power enterprise will reduce the proportion of thermal power.
4.4. Three Enterprises and Three Kinds of Energy. This section makes a comprehensive consideration on coal enterprise, electric power enterprise, and energy consuming enterprise and analyzes the game relationship among coal, thermal power, and other power. According to the model design, the profit function of the coal enterprise is shown in formula (14), the profit function of the electric power enterprise is shown in formula (23), and the cost function of energy consuming enterprise is shown in formula (6).

(1) Coal price rises, $\theta$, and tariff remains unchanged, so profit and cost fluctuation functions are shown below:

$$
\begin{aligned}
& \Delta \pi_{c}=\theta p_{c} \sum_{i=1}^{4} q_{i}, \\
& \Delta \pi_{e}=-\theta p_{c}\left(q_{3}+q_{4}\right), \\
& \Delta C_{u}=\theta p_{c}\left(q_{1}+q_{2}\right) .
\end{aligned}
$$

According to formulas (28), due to invariant energy consumption, electric power enterprise and energy consuming enterprise bear the extra profit of coal enterprise from coal price. Under the same tariff, energy consuming enterprise will compare the cost per unit of coal and that of electricity. When the price increases to a certain extent, it will reduce the purchase of coal and increase the consumption of electricity.

(1) When $p_{c}(1+\theta) \leq p_{f} / \varphi$, the energy consuming enterprise will maintain the current energy purchase ratio, and the enterprise is willing to bear the increase cost brought by coal price increase.

(2) When $p_{c}(1+\theta)>p_{f} / \varphi$, energy consuming enterprise will increase the consumption of electricity and reduce the use of coal, so electric power enterprise needs to increase the purchase of power, including coal and other power generation energy.

(3) When $p_{f} / \varphi-p_{c}(1+\theta)>p_{w} / \psi-\left(m_{3}-m_{4}\right)$, the thermal power cost is still less than other energy and, even rising the price, power enterprise will not reduce the proportion of thermal power but will bear more additional cost.

(4) When $p_{f} / \varphi-p_{c}(1+\theta)<p_{w} / \psi-\left(m_{3}-m_{4}\right)$, the thermal power cost is more than other energy; power enterprise will reduce the proportion of thermal power.

(2) Coal price rises, $\theta$, and the tariff rises, $\varepsilon$, so the profit and cost fluctuation functions are shown below:

$$
\begin{aligned}
\Delta \pi_{c} & =\theta p_{c} \sum_{i=1}^{4} q_{i}, \\
\Delta \pi_{e} & =\varepsilon p_{f} \frac{q_{3}+q_{4}}{\varphi}-\theta p_{c}\left(q_{3}+q_{4}\right), \\
\Delta C_{u} & =\theta p_{c}\left(q_{1}+q_{2}\right)+\varepsilon p_{f} \frac{q_{3}+q_{4}}{\varphi} .
\end{aligned}
$$

According to formula (29), profit fluctuation of coal enterprise is positive, profit fluctuation of power enterprise is 

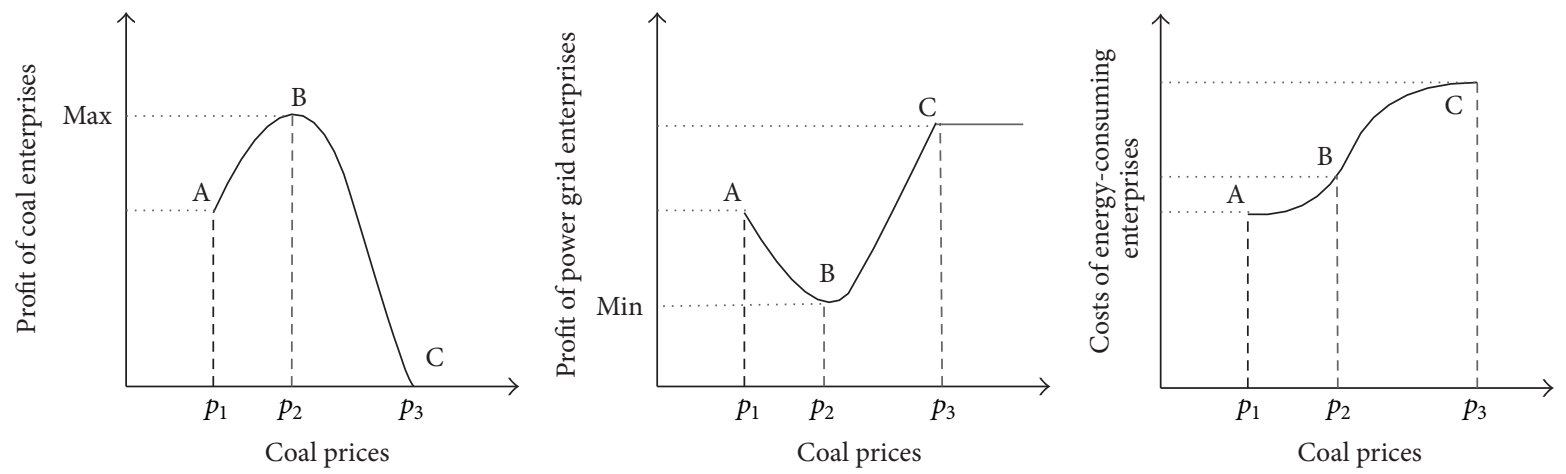

Figure 6: Association in effects of coal price fluctuation.

unknown, and cost fluctuation of energy consuming enterprise is positive. It shows that the cost of energy consuming enterprise is increasing, so energy consuming enterprise and power enterprise are taking the extra cost of the whole system.

(1) When $\theta p_{c}\left(q_{1}+q_{2}\right)<\varepsilon p_{f}\left(\left(q_{3}+q_{4}\right) / \varphi\right)$, energy consuming enterprise will not adjust the current energy purchase ratio.

(2) When $\theta p_{c}\left(q_{1}+q_{2}\right)>\varepsilon p_{f}\left(\left(q_{3}+q_{4}\right) / \varphi\right)$ and $p_{f}(1+\varepsilon) / \varphi-$ $p_{c}(1+\theta)<p_{w}-\left(m_{3}-m_{4}\right)$, the increased cost of coal is greater than thermal power in energy consuming enterprise, and the cost of thermal power is less than other power generation, so the enterprise will reduce the consumption of coal as soon as possible, even if all use electric energy in extreme case. The cost function of energy consuming enterprise is

$$
C_{u}=p_{f} \frac{\sum_{i=1}^{4} q_{i}}{\varphi}+p_{w} \frac{q_{w}}{\psi} .
$$

On the basis of formula (30), we can know that the cost of energy consuming enterprise only has one kind, which is the electric power. The source of power is different which is partly derived from the thermal power or other sources.

(3) When $\theta p_{c}\left(q_{1}+q_{2}\right)>\varepsilon p_{f}\left(\left(q_{3}+q_{4}\right) / \varphi\right)$ and $p_{f}(1+\varepsilon) / \varphi-$ $p_{c}(1+\theta)>p_{w}-\left(m_{3}-m_{4}\right)$, the increased cost of coal is greater than thermal power in energy consuming enterprise, and the cost of thermal power is more than other power generation, so the enterprise will all use electricity. Also, it will reduce the proportion of thermal power and increase the proportion of other power; the extreme situation is to all use other power generation energy. The cost function is

$$
C_{u}=p_{w} \frac{q_{w}}{\psi} .
$$

The cost of energy consuming enterprise only has one kind, which is the other power generation energy.

\section{Results and Discussions}

Through the game analysis of different enterprises and energy, it can be known that the change of coal price has different effects on the profit of coal enterprise, power enterprise, and energy consuming enterprise. When thermal power price changes with the coal price, profit fluctuation of coal or power enterprise and cost fluctuation of energy consuming enterprise will be different. According to the results, when coal and thermal power prices are changed, the association diagram is shown below which describes the change coal or power enterprise profit and energy consuming enterprise cost due to coal price fluctuation.

According to Figure 6, the influence of coal price fluctuation can be divided into three stages. We will define the current stage, single growth stage, double growth stage, and clean stage.

Among them, the A point and previous region is defined as the current stage. In this stage, the cost of coal is less than electricity, so energy consuming enterprise mainly uses coal. It is defined as a single growth stage from A point to $B$ point. In this stage, coal price has increased, and electricity price remains unchanged. Then the profit of coal enterprise is growing, profit of power enterprise will continue to decrease, and the coal cost of energy consuming enterprises is also growing.

At the B point, the profit is compressed to a certain extent, so electric power enterprise decides to raise the tariff. Thus, it is defined as a double growth stage from $B$ point to $C$ point, and coal price and thermal power price will rise in this stage, so cost growth rate of energy consuming enterprise will achieve the maximum and will continue to grow. When the coal cost is greater than electricity because of coal price growth, energy consuming enterprise will reduce the use of coal and even only use electricity. Profit of power enterprise will be increased with the rise of tariff, which continues to compress the profit of coal enterprise. Although power enterprise will increase the purchase of coal with electricity demand growth, the total profit of coal enterprise is declining in this stage.

When coal price and thermal power price grow to a certain extent, generation cost of other power is less than 
thermal power, and power enterprise will stop the use of thermal power and will all use other power, which is shown in the C point; after the point, coal sale volume is zero and profit is zero. Power enterprise would be only to buy other power, and thermal power price and coal price will not affect the profit, so profit of power enterprise and cost of energy enterprise have reached the maximum; they will no longer change with fluctuation of coal price. Since the adoptive energy in consumption enterprise is power and the power is all from other power generation, this stage is defined as clean stage. Connection points of each stage are mentioned in game analysis.

In order to analyze the characteristics of cobweb model in coal-electricity market, we need to make the fitting analysis according to actual data, but due to the lack of data, single growth and double growth stages are discussed.

(1) In single growth stage, when coal price rises, $\theta$, according to the profit function of coal enterprise, we can deduce that the slope of coal supply curve is $1+\theta$. In line with the profit function of electric power enterprise, it can be deduced that slope absolute value of coal demand curve is equal to 1 . Thus, the slope of the supply curve is greater than its absolute value, so web characteristic of coal-electricity market is convergence cobweb in this stage. It can be said that market can adjust coal price to a reasonable level by itself.

(2) In double growth stage, when coal price rises, $\theta$, and thermal power price increases $\varepsilon$, according to the profit constitution of coal enterprise, we can deduce that the slope of coal supply curve is $1+\theta$. In line with the profit function of electric power enterprise, it can be deduced that slope absolute value of coal demand curve is equal to $1+\varepsilon$.

(1) When $\theta>\varepsilon$, characteristic of coal market is convergence cobweb; in this case, market can adjust coal price to a reasonable level by itself and then reach a static Nash equilibrium.

(2) When $\theta<\varepsilon$, characteristic of coal market is divergent cobweb; in this case, if there is no government interference, the market will be in imbalance condition and this will lead to the unhealthy development of coal or electricity prices. Only compulsory intervention from government can help the healthy development of coal-electricity market.

(3) When $\theta=\varepsilon$, characteristic of coal market is closed cobweb; in this case, market can also adjust coal price by itself and make the market to be balanced in the long term.

\section{Conclusion}

Through the establishment of dynamic game analysis model for coal-electricity market, combined with game paths, this paper analyzes the competition for the market in different situations and draws the following conclusions:

(a) In the game analysis of coal-electricity market, it can effectively control the unhealthy competition between coal price and electricity price to introduce energy consuming enterprise as the third party. (b) When there are only coal enterprise and energy consuming enterprise, the coal market has first mover advantage. The profit that determines coal sales first is better and sales volume is two times that of the latter. At this time, the coal market reaches Starr Berg Equilibrium.

(c) Within a certain range, rise in coal price will increase the profit of coal enterprise. When price increases to a certain extent, due to the impact of electricity price and sales, it will lead to decline in profit, and coal sales fell to zero in extreme case, and then the profit of coal enterprise is zero.

(d) In a certain range, rise in coal price will squeeze the profit of power enterprise, leading to decline in profit. When profit fell to a certain extent, through the adjustment of electricity price and energy choice of energy consuming enterprise, the profit will rise, and it will not change with the rise in coal price.

(e) Rising coal price leads to the rise of profit in coal enterprise and cost of power enterprise and energy consuming enterprise. At the beginning stage, power enterprise and energy consuming enterprise share the additional cost. With the increase of tariff, coal enterprise and energy consuming enterprise share the additional cost.

(f) According to contrast of markup between coal price and tariff, if characteristics of cobweb are different in coal-electricity market, it needs to take different policy measures to regulate the market mechanism, so as to ensure the healthy development of the coal market.

\section{Competing Interests}

The authors declare that they have no competing interests.

\section{References}

[1] L. Zhenqiu, "Reconsideration of coal price contradiction," Price: Theory \& Practice, vol. 5, pp. 7-9, 2011.

[2] D. Lequn, Z. Huijing, H. Xing, R. Yan, and H. Pingli, "Analysis for influence of coal and electricity price linkage mechanism on electricity generation cost," Electric Power, vol. 9, pp. 19-22, 2007.

[3] Z. Zhang and M. Zhang, "Market power, confliction between coal and electricity and potential welfare lost," Industrial Economics Research, vol. 1, pp. 21-30, 2011.

[4] G. Liangjun, G. Zengjun, and Q. Yingwei, “Designing earnings coordination system for Chinese coal-electricity enterprises based on government regulation," China Soft Science, vol. 7, pp. 159-168, 2012.

[5] L. Fangzheng and W. Dan, "Reflection on the conflict between coal and electricity," Journal of Finance and Economics Theory, vol. 4, pp. 103-107, 2013.

[6] X. Pan, Z. Ren, W. Huang, and R. Wu, "Introduction to Nash equilibrium analysis and its application in electricity market," Electric Power, vol. 4, pp. 46-49, 2003. 
[7] Z. Xiaogang, C. Gang, and H. Qiping, "Nash equilibrium and the application on computer science," Journal of Wuhan University (Natural Science Edition), vol. 5, pp. 409-418, 2015.

[8] Y. Jie, J. Lei, and C. Hong, "Dynamic analysis in emergency management," Management Review, vol. 3, no. 46, pp. 50-64, 2005.

[9] L.-F. He, D.-Z. Zhao, and Y. Liu, "Side-payment self-enforcing contract based supply chain dynamic game coordination," System Engineering Theory and Practice, vol. 31, no. 10, pp. 18641878, 2011.

[10] R. Jiang, X. Qiu, and D. Li, "Multi-agent system based dynamic game model of smart distribution network containing multimicrogrid," Power System Technology, vol. 38, no. 12, pp. 33213327, 2014.

[11] Z. Shi, "First-mover advantages and after-mover advantages of oligopolistic firm," Academic Research, vol. 3, pp. 23-27, 2005.

[12] Z. Chunling, "Traditional first-mover and after-mover disadvantages analysis," Productivity Research, vol. 1, pp. 24-27, 2008.

[13] Z. Tan, C. Zhang, Y. Song, and S. Shen, "Distribution shift for wind power development in china: strategy analysis," Journal of Energy Engineering, vol. 141, no. 3, 2014.

[14] Y. Song, C. Zhang, Z. Tan, and Q. Shi, "Interregional electric power planning model based on sustainable development of wind power," Journal of Energy Engineering, vol. 141, no. 4, 2015. 


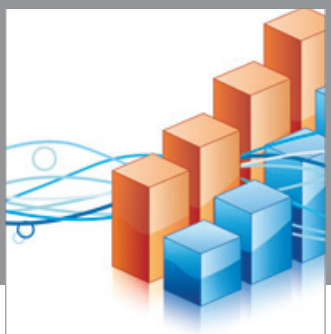

Advances in

Operations Research

vatem alat4

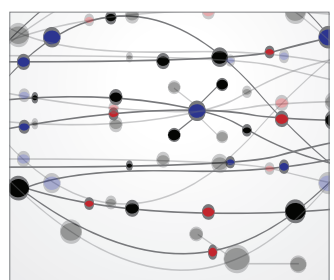

\section{The Scientific} World Journal
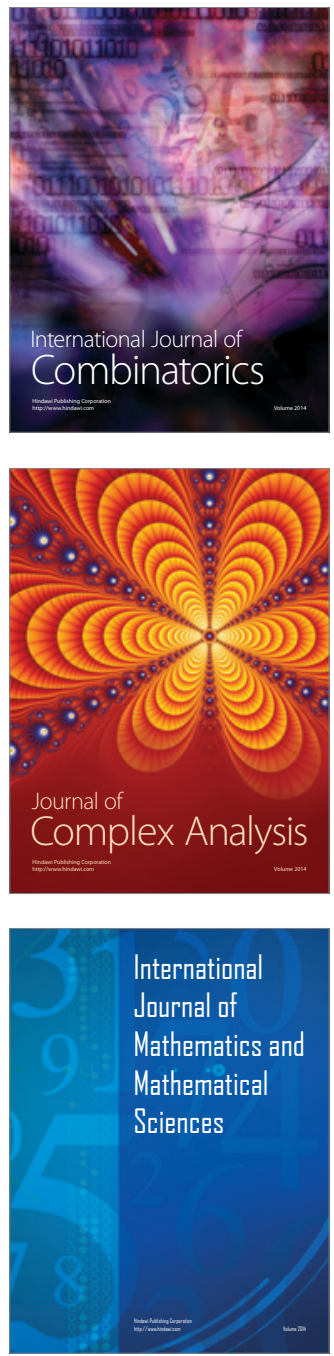
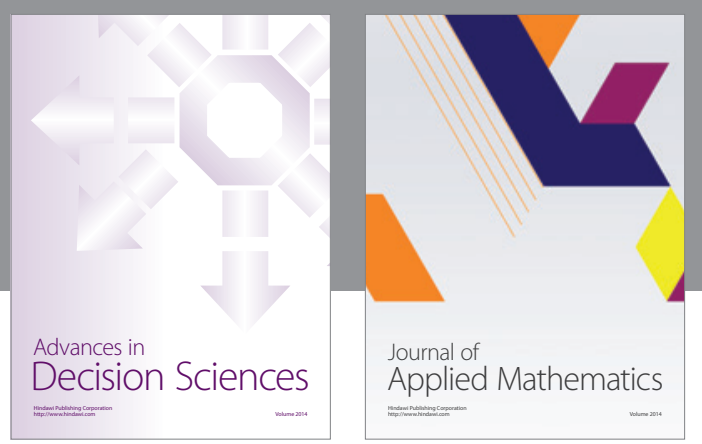

Algebra

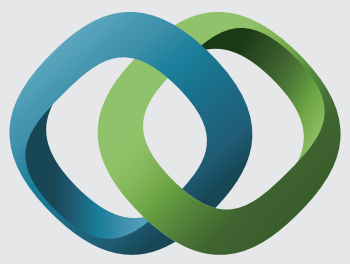

\section{Hindawi}

Submit your manuscripts at

http://www.hindawi.com
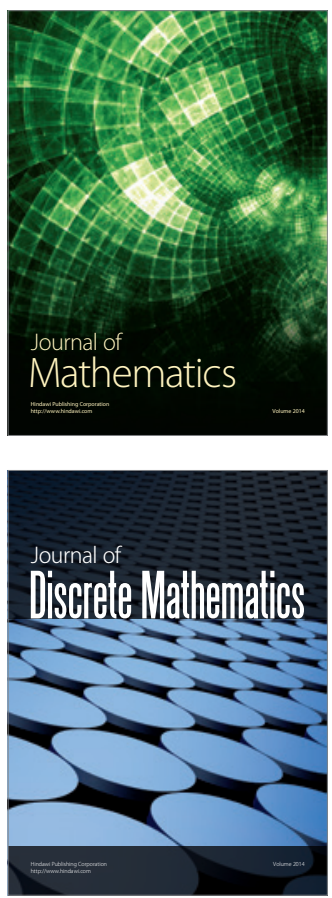

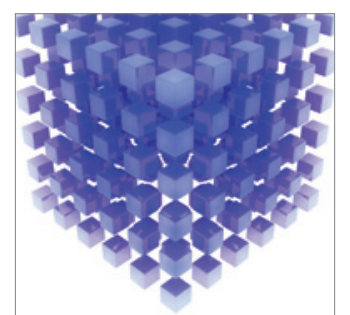

Mathematical Problems in Engineering
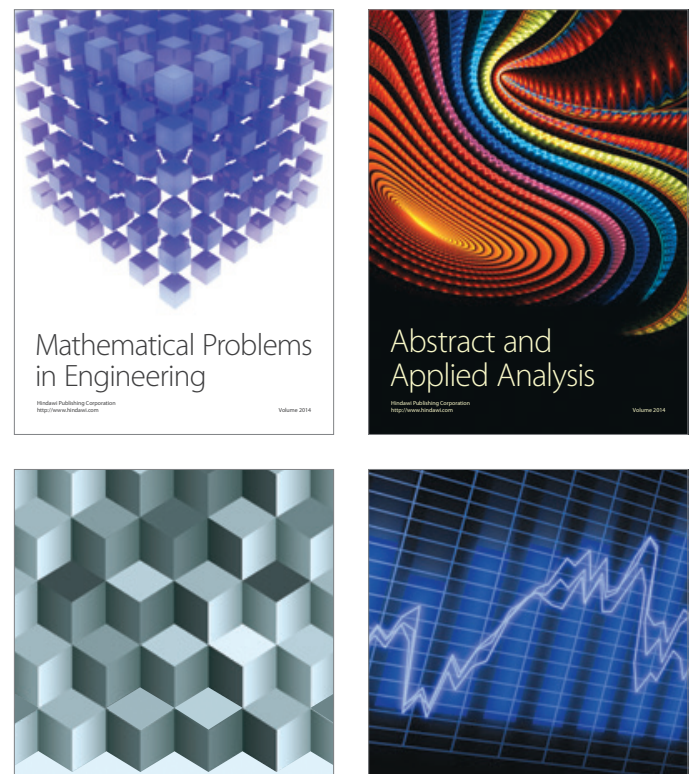

Journal of

Function Spaces

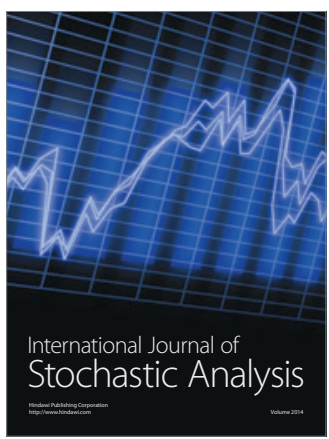

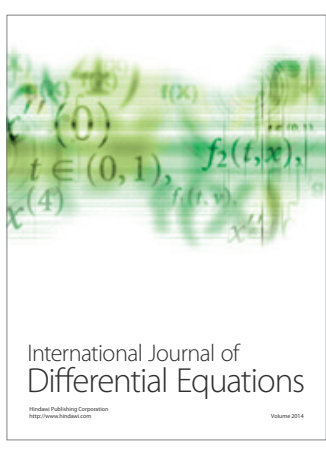
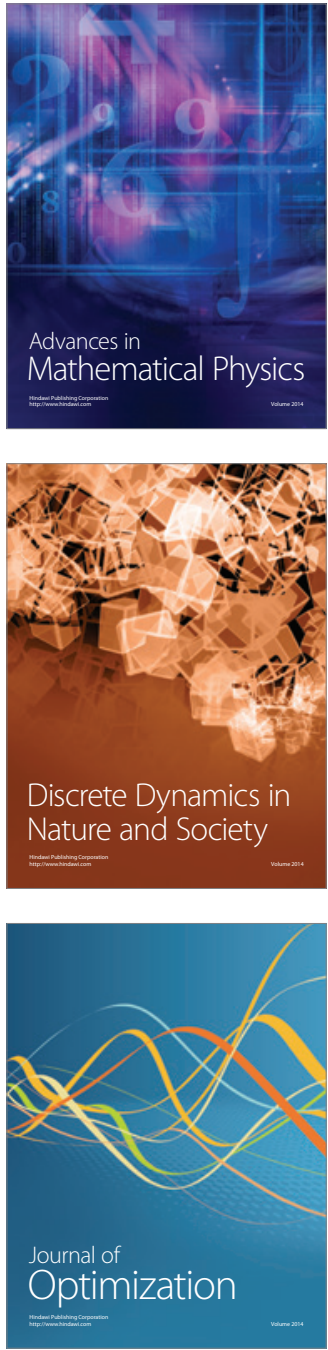